\title{
Luis de Pablo Hammeken. La República de la Música. Ópera, política y sociedad en el México del siglo XIX [1840-1870]. México: Bonilla Artigas Editores, 2018, 248 pp.
}

\author{
Jaime Cortés Polanía
}

$\mathrm{H}$ ace no mucho tiempo Celia Applegate afirmaba que "musicólogos e historiadores, junto a la gran mayoría de los humanistas, trabajan en una zona académica Schengen, en donde las personas cruzan las fronteras disciplinarias sin obstáculos, pero siguen siendo conscientes de las diferencias en el lenguaje, las costumbres, el conocimiento y las formas de realizar su trabajo". ${ }^{1}$ Luis de Pablo Hammeken contribuye a abrir tal tránsito transfronterizo con su libro La República de la Música, el cual deriva de su tesis doctoral en historia dirigida por Clara Lida y defendida en el Colegio de México en el año 2014. Es justamente Lida quien en un acertado y sintético texto de presentación se encarga de despejar posibles dudas ante las autoridades migratorias disciplinares, entre ellas, desorientados lectores en busca de una guía básica sobre ópera o acuciosos especialistas en busca de pormenorizados análisis musicales. En una primera frase, frontal e inequívoca, nos advierte: "Este no es un libro de la ópera ni un texto de musicología, sino un estudio social, cultural y político del mundo que se gestó alrededor de la difusión de la ópera en la Ciudad de México al mediar el siglo XIX” (p. 15).

Tal aclaración es un buen preámbulo a las preguntas básicas que orientan el trabajo de Hammeken: "quiénes eran las personas que en esa época asistían al teatro para presenciar una función de ópera, a qué sector social pertenecían y qué significado tenía este espectáculo para ellos y para el resto de la sociedad mexicana" (p. 22). De ellas se desprende el título del libro. Como el autor ha entrado a los temas de la musicología, pero no ha pernoctado en los territorios de esta disciplina, tal vez no haya otro título mejor al que eligió. En efecto, La República de la Música no se

* Profesor asociado, Instituto de Investigaciones Estéticas, Universidad Nacional de Colombia.

1. En el original: "Historians and musicologists, along with most humanists, work today in a Schengen zone of scholarship, where people cross disciplinary borders without hindrance yet remain conscious of differences in language, custom, knowledge, and ways of going about their work". Celia Applegate, "Introduction: Music Among the Historians", German History 30.3 (2012): 329. Traducción del autor. 
ocupa de las obras en sí mismas ni de sus compositores, tampoco de los libretistas ni de las tramas de sus libretos, sino principalmente del mundo de lo público - la res publica - en torno a la ópera, de aquellos que la hicieron posible en los teatros y que participaron de su expansión más allá de estos.

Como lo documenta Hammeken, ese conjunto social heterogéneo estaba integrado por mujeres y hombres que asistieron a los espectáculos, que desprevenidamente guardaron en su memoria pasajes emblemáticos de sus óperas favoritas o que los llevaron a sus casas en partituras impresas y manuscritas, muchas veces en versiones facilitadas. Además, lo conformaban comentaristas que le dieron sentido a las temporadas a través del uso de la palabra escrita en la prensa, o literatos que confirmaron el valor de la ópera más allá de los límites impuestos por la práctica musical. También estaba integrado por músicos y empresarios que se embarcaron en compañías con destino a Ciudad de México para cumplir sus aspiraciones profesionales, artísticas y económicas, y por políticos que detentaban el poder desde el aparato estatal y discrecionalmente decidieron otorgar las subvenciones necesarias para consolidar una actividad operística. Ciertamente, la ópera se constituyó en un proyecto plutocrático tan costoso en su despliegue como idóneo en su papel de configurar una imagen de nación civilizada en las órbitas del mundo occidental y en proceso de occidentalización.

Para dar cuenta de todo ello, el autor nos presenta su pasaporte disciplinar y sus deudas intelectuales más básicas: Eric Hobsbawm para la historia social, Peter Burke para la historia cultural y Clifford Geertz para su definición antropológica de cultura. También incluye una serie de referentes de la que en más de una ocasión ha emanado una especie de lingua franca no solo para musicólogos e historiadores, sino también para humanistas y científicos sociales en general: Pierre Bourdieu, Michel Foucault y Norbert Elias. No podían faltar títulos sobre asuntos más específicos en manos de Roger Chartier, Lawrence Levine y Gilles Lipovetsky, así como algunos pertinentes para la música del siglo XIX, entre ellos, Carl Dahlhaus, Susan McClary y Richard Lepperd. Si bien las críticas podrían señalar ausencias en musicología, el relevamiento sobre la ópera es lo suficientemente pertinente con autores como Paul Robinson, Daniel Snowman, William Weber, Theodore Rabb, John A. Davis y Carlotta Sorba, entre otros. Para el campo mexicano tampoco podían faltar las ineludibles citas a Enrique de Olavarría y Ferrari, y los trabajos recientes en manos de Aurea Maya Alcántara y Yael Bitrán. Sobre estos fundamentos el autor se esfuerza por construir una perspectiva de la historia social y cultural de la música a la que le será provechoso desplegar un diálogo teórico y metodológico con los argumentos de William Weber, Myriam Chimènes, Jeffrey H. Jackson y Stanley C. Pelkey quienes desde hace varios años llaman a una colaboración más estrecha entre historiadores y musicólogos, Jane J. Fulcher quien incluso apela a una "nueva historia cultural de la música", o José Geraldo Vinci de Moraes, Fátima Graciela Musri y Juan Pablo González que han planteado el problema desde América Latina. ${ }^{2}$

2. William Weber, "Toward a dialogue between historians and musicologist", Música e historia 1 (1993): 7-21; Myriam Chimènes, "Musicologie et histoire: Frontière ou 'no man's land' entre deux disciplines?”, Revue de Musicologie 84.1 (1998): 67-78; Jeffrey H. Jackson y Stanley C. Pelkey, 
La estructura del libro es coherente con su cometido. En la exposición subyace una cronología que obedece al tratamiento de temas específicos: la ópera como símbolo de civilización, la composición social del público y su diferenciación de género, el papel de los empresarios y los políticos. Tras de sí se revela un buen plan que, a medida que avanza, marca fronteras temporales claras: el inicio del período corresponde a la década de 1840, cuando la ópera se asentó como actividad frecuente e intensa durante el gobierno de Santa Anta, y el cierre llega con un quiebre, cuando los juicios de valor cambiaron conforme cambió la actividad musical - el distanciamiento de repertorios con la progresiva instalación de un canon - y la transformación de la arena política con la República Restaurada. Se abarcan así tres décadas de florecimiento de la ópera como el espectáculo musical más fastuoso y ambicioso en los confines de la capital mexicana. Con pericia narrativa, Hammeken no sacrifica la presentación de su evidencia sustentada en fuentes primarias desconocidas o poco trabajadas hasta ahora.

Una de las mayores insistencias gira en torno al poder civilizatorio otorgado a la ópera. A través de cruces de los testimonios de la época con las precisiones teóricas que beben de la sociología histórica de Norbert Elias, Hammeken demuestra cómo la actividad operática resultó siendo sinónimo de civilización, entendida a través de múltiples factores, entre ellos: la pedagogía del ciudadano en la modelación de sus comportamientos en un espacio público, pero cerrado y jerarquizado como el teatro; en su dimensión simbólica de lo político como demostración de la unidad de nación, ya sea en sus afinidades o deslindes ideológicos, y en su dimensión de género como espacio controlado para trazar imágenes sobre lo femenino y lo masculino. Aunque no es su objetivo ni su método, a futuro no sobra hacer alguna referencia a la civilización como término al que se le ha seguido la pista en una reciente historia conceptual, que tal vez algo pueda añadir a una historia social y cultural de la música como esta. ${ }^{3}$

Por otra parte, los adeptos a una visión comparativa extrañarán algunos cruces a nivel latinoamericano. Son entendibles las referencias a las añejas síntesis de Gerard Béhague y Nicolas Slonimsky, sin embargo, las más recientes, como la de Consuelo Carredano Fernández y Victoria Eli Rodríguez, y las más críticas, como la de Ricardo Miranda y Aurelio Tello, constituyen otras puertas de entrada más

eds., Music and History: Bridging the Disciplines (Jackson, Miss.: University Press of Mississippi, 2005); Jane J. Fulcher, "Introduction: Defining the New Cultural History of Music, its Origins, Methodologies, and Lines of Inquirity", The Oxford Handbook of the New Cultural History of Music, ed. Jane J. Fulcher (New York: Oxford University Press, 2011) 3-14; José Geraldo Vinci de Moraes y Elias Thomé Saliba, História e Música no Brasil (São Paulo: Alameda, 2010); Fátima Graciela Mursi, "Relaciones conceptuales entre musicología e historia: análisis de una investigación musicológica desde la teoría de la historia”, Revista Musical Chilena 53.192 (1999): 13-26; Juan Pablo González, "Presentación del dossier "Escuchando el pasado: música y sonido en el entramado histórico y social", Historia Crítica 57 (2015): 13-17.

3. Nos referimos aquí particularmente a Javier Fernández Sebastián, dir., Diccionario político y social del mundo iberoamericano. La era de las revoluciones, 1750-1850. [Iberconceptos II] (Madrid: Universidad del País Vasco, Euskal Herrico Unibersitatea / Centro de Estudios Políticas y Constitucionales, 2014). 
actualizadas. ${ }^{4}$ En todo caso, tales puertas ya se han abierto con trabajos más específicos y profundos, entre ellos el de Maria Alice Volpe sobre la ópera en el siglo XIX brasileño o el de Annibale Enrico Cetrangolo sobre el caso argentino; no obstante, ambos se ocupan de un período posterior al escogido por Hammeken. ${ }^{5}$ Por supuesto, no puede entenderse esto como una falencia, sino más bien como una agenda pendiente que confirma lo obvio: la falta que hace un panorama amplio en el que podamos avanzar en la comprensión histórica y musical de uno de los fenómenos más intrigantes, abarcadores y llamativos del siglo XIX latinoamericano.

DOI: $10.17533 /$ udea.trahs.n14a12

4. Consuelo Carredano Fernández y Victoria Eli Rodríguez, eds., Historia de la música en España e Hispanoamérica. La música en Hispanoamérica en el siglo XIX, vol. 6 (Madrid: Fondo de Cultura Económica, 2010); Ricardo Miranda y Aurelio Tello, La música en Latinoamérica. La búsqueda perpetua: lo propio y lo universal de la cultura latinoamericana, vol. 4 (México: Secretaría de Relaciones Exteriores, Dirección General del Acervo Histórico Diplomático, 2011).

5. Maria Alice Volpe, "Indianismo and Landscape in the Brazilian Age of Progress: Art Music from Carlos Gomes to Villa-Lobos, 1870s-1930s" (Tesis de doctorado, University of Texas at Austin, 2001); Annibale Enrico Cetrangolo, "Ópera e identidad en el encuentro migratorio. El melodrama italiano en Argentina entre 1880 y 1920" (Tesis de doctorado, Universidad de Valladolid, 2011). 